Zagadnienia Rodzajów Literackich, LX, z. 3

PL ISSN 0084-4446

DOI: $10.26485 / Z R L / 2017 / 60.3 / 8$

Aleksandra Mochocka

Uniwersytet Kazimierza Wielkiego w Bydgoszczy*

\title{
Transmediation of Spatial Characteristics - Mervyn Peake's Gormenghast Series and Philip Cooke's Gormenghast: A Board Game set in the World of Mervyn Peake
}

\begin{abstract}
The text discusses notable spatial characteristics of the storyworld created in Mervyn Peake's Gormeghast literary series and relates them to the mechanics used in a paratextual board game designed by Philip Cooke. Spatiality is crucial in Peake's series, thus allowing for a specific relationship between literary pre-text and the board game as a medium that allows participation. The text thus tries to answer the questions how the Gormenghast storyworld utilises spatial categories, how the spatiality of the novels represents certain "transfictional affinity" with board games, and how the board game utilises game mechanics to convey the affect and pathos of the pre-text.
\end{abstract}


* Instutut Neofilologii i Lingwistyki Stosowanej Uniwersytetu Kazimierza Wielkiego w Bydgoszczy ul. Curie Skłodowskiej 56/371, 85-088 Bydgoszcz e-mail: aleksandra.mochocka@gmail.com 
The following considerations concern spatially determined characteristics of the storyworld constructed in Mervyn Peake's Gormenghast series and their transmediation into a board game, and constitute a part of my research on the narrative affordances of board games and the design strategies employed in the creation of the so-called paratextual board games. The term denotes the category of games that (usually) belong to a certain media franchise but "exist in a more complex relationship with their corresponding text than other ancillary products do - they are both part of and apart from the main text" (Booth 2015: n.p.). A game of this kind would utilise game mechanics to facilitate gameplay that results in meaningful play when supported with the proper interpretative baggage (Salen and Zimmerman 2004: 34), allowing for an experience similar to the one felt while approaching the other constituents of the transmedia system. On the other hand, the game should be playable for those who have had no previous contact with the aforementioned system.

The following analysis relates to Booth's observation that in the case of such board games the process of transmediation consists not only in the transmission of plot-related aspects of narrative, but first and foremost the inclusion of affect and pathos, which can be manifested, in turn, by what Booth specifies as spatial and temporal understanding (Booth 2015: n.p.). As a medium, board games are first and foremost games, that is interactive systems allowing for meaningful play via player agency and system feedback: in other words, the players make informed choices that influence the state of the system (Salen and Zimmerman 2004: 34-36). Game mechanics is a salient feature of board games, as players have to engage directly in the application of the constitutional rules (Salen and Zimmerman 2004: 130) by performing all the required calculations, checking them against the operational rules (Salen and Zimmerman 2004: 130), etc., effectively acting as a human computing machine; following Lev Manovich, Booth observes that analogue as they are, board games represent modularity, which is a feature of new (digital) media (Booth 2015: n.p.).

As to questions of "playability" versus "narrativity" of games, nowadays the consensus is that both can be found in games, albeit not necessarily equally in all games (Jenkins 2004: 119), and definitely not at the same time (Ryan 2001: 199). Board games appear to be decisively more "game-like" and less "story-like" than, for example, cRPG video games or larps, but than again particular sub-genres as well as specific cases should be 
considered. Just as other game genres, board games enable the narrative processes through evocative spaces, and rely on enacted and embedded narratives to communicate narrative information (Jenkins 2004). Another crucial aspect to be taken into account here is the ludonarrative coherence, which is the opposite of the ludonarrative dissonance as defined by Hocking (Hocking 2009: 240). If there is a narrative present, game mechanics should be structured in such a way so as to support the overlaying narrative aspect of the game rather than contradict or undermine it. Board games are, by definition, spatial, and numerous board game mechanics are related to movement, area development and control, and other spatially motivated actions. In the light of this, a literary text that has got a strong focus on spatiality seems to possess specific "transfictional affinity" with board games. The following text discusses how Gormenghast: A Board Game Set in the World of Mervyn Peake (2013) uses game mechanics, such as Hand Management, Pick-up and Deliver, and Tile Placement ${ }^{1}$, to recreate the affect and pathos characterising Peake's texts.

The observations pertaining to Peake's series are partially based on my unpublished Master's thesis Inside the Walls. Space inside Gormenghast Castle in Mervyn Peake's The Gormenghast Trilogy, written under the supervision of Prof. David Malcolm at the University of Gdańsk in 1999, and contain revised and significantly expanded fragments of the same. The following section discusses the aforementioned features of Peake's Gormenghast series (specifically Titus Groan and Gormenghast). Questions how this spatiality represents certain "transfictional affinity" with board games, thus enabling the transmediation from a literary pre-text, are going to be discussed in the second section, along with specific strategies used in Philip Cooke's Gormenghast: A Board Game Set in the World of Mervyn Peake.

\section{Space in Peake's Gormenghast series}

In the Gormenghast series "it's the place rather than the plot that remains in the mind" (Winnington 2006: 5); what is more, "Peake does not organise his narrative chronologically or by following one particular character, but as a dramatised 3rd-person telling of the life of the Castle, in a voice which might almost be that of the stones themselves" (Sussner et al. 2006: 242). The space presented is limited to a fragment of fantastic reality, "the penultimate example of overpowering setting" (Shlobin and Shlobin 2000: 157), constituting the world of a self-sufficient closed structure text. The spatial model utilised here is taken from the Gothic tradition, to be transformed into an autonomous, "anomalous" (Winnington 2006: 2) work.

Spatial organisation may dominate over the other elements of a literary text, becoming the focus of interest (Głowiński, Okopień-Sławińska and Sławiński 1991: 241), and serving as a genre marker. Thus, the decaying castle is an important feature of the Gothic novel, representing "the attractions of tyrannous strength and melancholy" (Tompkins 1990: 87). The castle allows to introduce the subject of imprisonment, functioning as "a limited fragment of being, (...) where consciousness is forced back on itself” (Tompkins 1990: 88).

\footnotetext{
1 The terms denoting various game mechanics that appear in this text have long been used by various board game designers and players, and can be found, for example, on The Board Game Geek site: https://boardgamegeek.com/browse/boardgamemechanic

2 The series comprises of three novels, Titus Groan, Gormenghast, and Titus Alone, published originally in 1946, 1950, and 1956, respectively. A novella, Boy in Darkness (1956) and a posthumously published novel, Titus Awakes (2009), not to be discussed here, are sometimes included in the series as well.
} 
Space in the Gormenghast novels is often "loosely called Gothic", yet at the same time it is "only tenuously deriving from the traditional Gothic novel" (Binns 1979: 21). One has to remember that "the American edition of Titus Groan was subtitled A Gothic Novel, against the wishes of the author" (Morgan 1960: 79; emphasis mine). On the other hand, it would be difficult to justify the rejection of any links between the Gothic tradition and the Gormenghast texts, specifically when it comes to the presentation of space. As Gomel has it,

In the Gothic, space is not Newtonian: it is twisted into claustrophobic mazes, inescapable dungeons, and haunted castles where the past collides with the present. The brooding landscapes of the Gothic express the fears, foreboding, and insights that have no voice in realism. And the Gothic is not alone; later in the nineteenth century it is joined by other nonrealistic genres, such as fantasy, SF, the ghost story, the lost world novel, and others. All of them utilize impossible narrative topologies. (Gomel 2014: 11)

If not directly situated into the ranks of Gothic fiction, or amongst the texts that follow it openly, the Gormenghast novels belong to "literature of desire, which seeks that which is experienced as absence and loss" (Jackson 1981: 2-3).

The Gothic novel tradition is one of the sources of the category termed a "closed structure" novel, relaying on "the very high intensity of focus" (Spencer 1971: 27). Generally speaking, delimitation of space creates the isolation of the world from empirical reality and enhances tension between its elements (Zgorzelski 1975: 12-13). The autonomy of the limited space allows for the lack of verisimilitude; what is presented in the closed structure text is:

a world in itself: a self-enclosed, private, very intense, and often extremely haunting world in which the accustomed types of literary characters and the usual relationships in time and space are inappropriate. The closed structure depends for its enclosure upon the restriction of the perspective to one exclusively maintained emotional and intellectual attitude toward the subject. (Spencer 1971: 2-3)

The closed structure novel is distinguished by "the subordination of character to a total vision spatially conceived" (Spencer 1971: 30). It relies on the reduction of characters to the functions they possess in the narrative, and the mutability of their identities (Spencer 1971: 32). The subjection of characters to the spatial vision has a cinematic effect: characters are "entirely overshadowed by the physical presence of their surroundings" (Raban 1968: 113), "minutely attuned to one another" (Raban 1968: 119).

Spots of indeterminacy exist in every text (Ingarden 1988: 282), yet while it is natural for the space presented in literary texts to possess spots which need concretisation, the predominance of the indeterminate space is characteristic of fantasy in particular. "The topography, themes and myths of the fantastic all work together to suggest this movement towards a realm of non-signification, towards a zero point of non-meaning" (Jackson 1981: 42). This kind of writing "is preoccupied with limits, with limiting categories, and with their projected dissolution" (Jackson 1981: 47, 48). As follows, a crucial feature of the fantastic is the tendency to non-designation: 
(...) the shady worlds of the fantastic construct nothing. They are empty, dissolving. Their emptiness vitiates a full, rounded, three-dimensional visible world, by tracing in absences, shadows without objects. Far from fulfilling desire, these spaces perpetuate desire by insisting upon absence, lack, the non-seen, the unseeable. (Jackson 1981: 45)

Fantastic landscapes are "relatively bleak, empty, indeterminate (...), less definable as places than as spaces, as white, grey, or shady blanknesses" (Jackson 1981: 42); what is presented is "the hollow world, one which is surrounded by the real and the tangible, but which is itself empty, mere absence" (Jackson 1981: 42). Problems of vision are "one of the central thematic concerns of the fantastic" (Jackson 1981: 45). "In a culture which equates the 'real' with the 'visible' and gives the eye dominance over other sensitive organs," says Jackson, "the un-real is that which is in-visible" (Jackson 1981: 45).

Space in the Gormenghast castle is highly problematic: on the one hand it is constructed in accordance with fundamental principles of human cognition, thus fitting in with "the notion of prototypical human experientiality" (Fludernik in Gomel, 2014: 4), yet on the other hand it carries some characteristics of an unnatural narrative that "can radically deconstruct our real-world notions of time and space" (Alber et al. 2010: 116). The universality of spatial concepts can be ascribed to the fact that the basics of physical environment and human physiology are invariable, regardless of the cultural context; arbitrary as they are, orientational metaphors can be explained in terms of human experience, both physical and cultural (Lakoff and Johnson 1980: 14). As follows, if a text utilises basic orientational metaphors (such as the IN-OUT image schema), it appeals to "the most pervasive features of our bodily experience" (Johnson 1987: 21) and familiarises the storyworld. In Peake's Gormenghast series there is the merger of such familiarising presentation of space as approachable and understandable (and thus, possibly meaningful) with defamiliarising creation of unnatural, and therefore uncanny, non-signifying space. The power of Peake's work originates from the tension between the two contradictory elements, "the blending of the familiar and the strange often purely through the effects of conjunction" (Gardiner-Scott 1988: 15-16).

"Most discussions of spatial practices" are grounded in the Newtonian notions of timespace applied to the classic theories of experientiality, such as Lakoff and Johnson's theory of cognitive metaphors (Gomel 2014: 4). However, there are also "textual topologies that defy the Newtonian-Euclidean paradigm of homogenous, uniform, threedimensional spatiality" (Gomel 2014: 3), and "that representation of impossible spaces is an integral part of the narrative poetics of modernity and postmodernity" (Gomel 2014: 6, original emphasis). Peak grounds his depictions in the cognitive metaphors and at the same time achieves the non-Newtonian, non-Euclidean effects, establishing an unnatural storyworld that "contains physical or logical impossibilities that concern the represented world's (...) spatial organization" (Alber et al. 2010: 116).

As it is going to be illustrated with selected examples below, in the discussed novels "there is remarkably little to instruct the eye. Despite the unfamiliarity of the setting, the text does not specify if the Tower of Flints is round or square, or whether the arches of Gormenghast are roman or gothic" (Winnington 2006: 25). Although Peak is usually recognised as "an artist, with a strongly developed visual imagination" (Morgan 1960: 74), in his texts "the visual references are comparatively weak and vague" compared to references to other senses, such as hearing or touch (Winnington 2006: 26), evoking "sensory 
memories" (Sanders 2001: 460). "Whenever Peake writes of visual perception, he underlines its selectiveness: what we see depends not upon the optical qualities of the eye but on the heart and mind behind it" (Winnington 2006: 192). The readers who recreate the spatial vision "have unconsciously performed Peake's 'vast alchemy' and transmuted their impressions from one perceptual mode to another" (Winnington 2006: 26).

The castle is depicted as possessing enormous dimension: "Distance was everywhere the sense of far-away - of detachment. What might have been touched with an outstretched arm was equally removed, withdrawn in the grey-blue polliniferous body of this air" (Peake 1992: 300). This introduces the distorted perspective: "Nothing is quite what it seems, depending on the angle of mind or eye, and the element of surprise is always a possibility, even if it is predominantly mediated through the often obvious third-person narrator" (Gardiner-Scott 1988: 17). The interest seems to be in the problem how vision, being a means of perception, is distorted by the distance at which things are seen, as in the following example: "The Hall of Spiders yawned and shrank, the threads deceiving the eye, the distances, shifting, surging forward or crumbling away, to the illusory reflectings [sic] of the moon" (Peake 1992: 312). The idea of perspective, the "central theme - one crucial to [Peake] as artist and writer" (Gardiner-Scott 1988: 13), is brought up throughout the text, apparent in the numerous fragments when the characters look outside their windows, as the size of the castle makes everything diminished and shrunk: "Between high bastions might be seen, hundreds of feet beneath, a portion of quadrangle wherein, were a figure to move across, he would appear no taller than a thimble" (Peake 1992: 54).

The opposition "open-closed" is one of the two most frequent spatial notions which organise texts (Lotman 1984: 310-311), and "our encounter with containment and boundedness is one of the most pervasive features of our bodily experience" (Johnson 1987: 21). The IN-OUT orientation entails protection from or resistance to external forces; limitation, and restriction of the forces within the container; relative fixity of location; and limitation of the view of the object (Johnson 1987: 22). The symbolic meaning of the barrier, reflected in language (e.g. "wall of prejudice"), and present in literary heritage (e.g. Edward Bond's Lear or Jean Paul Sartre's Le Mur) and popular culture (e.g. the cult album by Pink Floyd) is linked to the primary function of such constructions: to protect by separation from dangers. Safety and comfort are gained at the expense of communication with the outer world. "The fear of solitude (...) is the price of freedom" (Fiedler 1990: 134).

In Peake's texts, the castle is surrounded by the high Outer Wall; there are also enclosures inside the castle, for example Irma's garden, not to mention innumerable walls of corridors and rooms. The motif is utilised, for example, when the Poet erects a makeshift barrier that could separate him from a stranger (Peake 1992: 100). The isolation of the castle is directly linked with its self-sufficiency. The exchange of basic goods between the castle and the Mud Dwellers is reduced to a minimum; communication is non-existent (Peake 1992: 8). There are some disjointed remarks, however, that suggest something to the contrary: "Though represented as a separate world, feudal and pre-industrial, twentieth-century phrases and concepts appear discreetly in the text: Peake talks of sociologists, Steerpike decides that Barquentine is 'to be liquidated' — an expression new to George Orwell as late as 1938” (Binns 1979: 27). 
Gormenghast castle has its own kitchens, schools, and small manufactures. The ultimate example of such fortress-like self-sufficiency is Rottcodd, whose "meals came up in a miniature lift through darkness from the servants' quarters many floors below and he slept in the ante-room at night and consequently he was completely cut off from the world and all its happenings" (Peake 1992: 12). The characters want to be "in their own realms again" (Peake 1992: 461), as Fuchsia does: "Looking down from her little window upon the roofs of the castle and its adjacent buildings she tastes the pleasure of her isolation" (56). The presentation of separate spaces inhabited by solitary dwellers adds to the effect that "Peake focuses on the individual, often solitary by choice, and offers only fragmentary glimpses of society, with little sense of social cohesion" (Winnington 2006: 36).

Specific fragments of space and their inhabitants constitute inseparable pairs, as it is the case with Rottcodd and the Hall of Bright Carvings, Fuchsia and the Attic, Swelter and the Great Kitchen, or Countess and her bedroom, to name only a few; nearly all characters are firmly set in a carefully fitted space — they never move beyond its limits. The private spaces and the characters are interconnected. In some cases it can be explained by the characters' influence on their environment. For example, the teachers are in charge of arranging their personal spaces: Fluke's space is a shambles while Perch-Prism's is sterilely clean. On the other hand, the submissive servants called Grey Scrubbers literally merge with their environment: "Through daily proximity to the grey slabs of stone, the faces of the Grey Scrubbers had become like slabs themselves" (Peake 1992: 16).

The spots of indeterminacy prevail over the space which is depicted; at the same time, diminutive fragments of the world are described in detail. Peake plays with "with a judicious mixture of the piling on visual images, details and scale" (Gardiner-Scott 1988: 17). The most distinctive techniques applied here can be divided into five main categories, namely: the one used for dimension, details, volume, light, and colour.

The castle is gigantic, yet the dimension of its buildings is often given in exact numbers. For example, the shelf in the wall is two hundred to three hundred feet long (Peake 1992: 7). There are numerous instances of correct calculations on the part of the narrator and the characters ${ }^{3}$, and the interest in precise numerical dimension merges with the second category, that is the presentation of seemingly redundant details. An example would be Steerpike's room:

In the centre of the room was a simple stone table. Upon it, and grouped roughly at its centre, were a whorl-necked decanter of wine, a few sheafs of paper, a pen, a few books, a moth pinned to a cork, and half an apple. (Peake 1992: 379)

The "spotlight technique" tends to be combined with the use of numericals, again: the appearance of details often functions as less important than their exact number.

The passages and corridors of the castle are invariably narrow. This results in "a restricted view" (Peake 1992: 55), and problems with entering and leaving closed spaces. There is no grand gate to the castle. Passing through entrances requires crawling or at

3 The technique is visible in the fragment describing Steerpike's climbing on the roofs:

This time, leaning precariously out over the sill and with his face to the sky, he scrutinized the rough stones of the wall above the lintel and noticed that after twenty feet they ended at a sloping roof of slates. (...) The twenty feet above him, almost seeming at first to be unscalable, were, he noticed, precarious only for the first twelve feet where only an occasional jutting of irregular stone offered busy purchase. (Peake 1992: 89) 
least lowering the body, as when Fuchsia "ducking her head crept through the narrow opening and found herself at the lowermost steps of the flight that led upwards in dark spirals" (54).

When it comes to light, "the slow drama of Gormenghast continued among shadows" (Peake 1992: 242). There are numerous repetitions of words such as "darkness" or "night". Natural light penetrates the castle through cracks in the walls and smeared window panels: "Above the stone flight the sloping roof was in so advanced a state of disintegration that a great deal of light found its way through the holes in the roof, to lie in golden pools all over the great flight of stairs (...)" (Peake 1992: 460). Then again, artificial light predominates inside the walls. For example, there is only one window in the Hall of Bright Carvings, hidden behind shutters: "Even on a hot, stifling, unhealthy afternoon such as this, the blinds were down and the candlelight filled the room with an incongruous radiance" (Peake 1992: 9-10). When a downpour deprives the castle of the remnants of light, artificial illumination is used, too (Peake 1992: 566).

The most frequently used colour terms used in the descriptions of the castle are, as follows: white, black, red, yellow, blue, green, brown, purple, and grey. Their derivatives (for example, pink, coral, or indigo) or shades (such as lemon yellow or deep green) are present, but not as recurrent epithets. The dominant colour note belongs to red. Such a colour scheme is suggestive of the eleven basic colour categories as distinguished in relationship to human perception (Berlin and Kay 1991: 2). The primeval distinction is the presence and absence of light; a universal rule is that "if a language contains three terms, then it contains a term for red" (Berlin and Kay 1991: 2). Appealing to basic cognitive schemes, colour coding in Peake's texts also adds to the universality of the Gormenghast series.

The castle is governed by its entropic drive, "inhabited by two classes, an aristocracy and their faithful servants, all arrested in their development, fixated on empty and absurd rituals" (Binns 1079: 26). Everything is dilapidated, crumbling into pieces. Degeneration concerns objects of everyday use:

Fuchsia (...) sat down in front of a mirror that had smallpox so badly at its centre that in order to see herself properly she was forced to peer into a comparatively unblemished corner. Her comb, with a number of its teeth missing (...). (Peake 1992: 385)

The same applies to long forgotten mechanisms (Peake 1992: 54) and the lighting equipment (Peake 1992: 35). Apart from the over-cleaned quarters of Irma Prunesquallor and Steerpike, every other room is in a state of chaos, the Countess's bedroom as the best example: "The room was untidy to the extent of being a shambles. Everything had the appearance of being put aside for the moment" (Peake 1992: 35). The family's Attic is presented as a repository of all things broken and worn out (Peake 1992: 46, 54). Even Irma's place is not as orderly as it seems:

What she lacked was the power to combine and make a harmony out of the various parts that, though exquisite in themselves, bore no relationship either in style, period, grain, colour or fabric to one another. (Peake 1992: 520)

The family's activity is directed in the wrong way: instead of cleaning/ordering their environment, they clutter/disintegrate it, and the entropy increases. 
Most rooms look as if they were forgotten. Those neglected places are visited only in transition, which happens rarely and with selected characters only. However, there are also rooms prepared to be used even though no one is ever visiting them, such as, for example, the Christening Room, decorated with flowers by Pentecost (Peake 1992: 68). Pentecost's activity, though seemingly productive, serves nothing, as no one can admire the floral compositions. Another example would be the Room of Roots. The Twins have devoted three years of arduous work to paint it, as they wanted the place to be colourful in order to attract birds, but the birds would not go there (Peake 1992: 181).

Gormenghast is illogical and incomprehensible, even for the characters that occupy it. Perhaps it had some meaning, but it has been forgotten. Its purpose remains in the past. The castle is full of places that cannot be explained in terms of purpose or functionality. No reasons behind their existence is ever given. The fantastic sense of absence and loss comes into being here, often combined with admiration and delight, as in the following fragment:

\begin{abstract}
He had seen a tower with a stone hollow in its summit. This shallow basin sloped down from the copperstones that surrounded the tower and was filled with rainwater. In this circle of water whose glittering had caught his eye, for him it appeared the size of a coin, he could see something white was swimming. As far as he could guess it was a horse. As he watched he noticed that there was something swimming by its side, something smaller, which must have been the foal, white like its parent. (Peake 1992: 97)
\end{abstract}

This specific fragment is often commented on, with Morgan observing that "these horses are not like Chekhov's gun; they don't have to be there. But it is such details - details here of a world within a world — that make the fantasy leap into verisimilitude" (Morgan 1960: 79). However, detailed depiction of the world notwithstanding, "the castle is space without significance" (Shlobin and Shlobin 2000: 157). The space in the castle is seemingly comprehensible, but it is only an illusion built upon universal ordering principles and orientational metaphors. The space lacks meaning, which brings forth Alber's idea that "arguably, the logically impossible is even stranger and more disconcerting than the physically impossible, and we have to engage in even more extensive cognitive processing to make sense of it" (Alber 2009: 80).

In the light of the aforementioned remarks, it could be said that spatiality is essential in the Gormenghast storyworld. While the delimitation of space is executed here in a way suggestive of the Gothic tradition, Peake was successful in creating autonomous closed structure novels belonging to the fantasy tradition by the merit of their preoccupation with indeterminacy, isolation (lack of connection with the outer world), and limits (distance and barriers). While the texts utilise fundamental orientational metaphors related to human bodily experience, they use them to achieve defamiliarising effects.

\title{
Gormenghast spatiality transmediated
}

As it has been discussed in the previous section, there are two dominant features of Gormenghast literary storyworld: a strong focus on spatiality and, at the same time, the prevalence of the spots of indeterminacy over the designated space. Gormenghast spatiality has been utilised in the EU Framework 6 IST Integrated Research Project "NM2: New Media for the New Millennium" to create "a 3D digital environment (...) developed as interactive interface between the interactor and the mixed media authoring tools" 
(Sussner et al. 2006: 243). The project used the BBC television series Gormenghast (2000) as the immediate source material. Winnington observes that "no visual representation of [Peake's] world, such as a television adaptation, can please everyone" because the pre-text representation is, in fact, undetermined (Winnigton 2006: 25). Still, the spectatorial reception of Peake's literary work was meant to be changed into participatory, active authoring practices (Sussner et al. 2006: 243). This project was heavily dependant on environmental storytelling, subjugating narrative to navigation in space. Yet another project that utilises Gormenghast spatiality is Philip Cooke's Gormenghast: A Board Game Set in the World of Mervyn Peake, published in 2013 by Sophisticated Games Ltd. and The Overlook Press. The focus in this discussion is going to be on the game mechanics, and the resulting enacted and emergent narratives, rather than the outer dimension of the game, that is the shape, size, texture, and weight of the components, and the iconography and typography featured on the components ${ }^{4}$.

Transmediating literary texts, board games utilise various strategies to find the balance between referentiality and playability. The basic choice in adapting from a medium that tells (literature) to a medium that enables interaction (a game) (Hutcheon 2006: 12-13) is either to try and recreate a specific narrative, or to abandon such an attempt at all. But declining to render a story in a paratextual board game does not solve all the problems. The components of a storyworld, such as existents, setting, physical laws, social rules and values, events and mental events (Ryan 2014: 34-37), all have to submit to the "playability" of the game; needless to say, all of them have to be transferable to the medium affordances of a board game.

The game has been published as a cardboard box containing movable elements (tiles, cards, Book of Ritual booklet), a die, and the instructions book. The rule book features a quotation from Titus Groan, plus a very brief introduction to Gormenghast, and a synopsis of Titus Groan and Gormenghast, followed by one paragraph of a commentary on Peake's "further work" (Cooke 2013b: 2-3). There is also some information about Mervyn Peake and "Special Thanks" section, in which the Peake family, as well as G. Peter Winnington, and their collaboration with the designer is mentioned (Cooke 2013b: 7). All these fragments are extremely short and sketchy.

To play the game, one does not need to know the Gormenghast novels at all, but being acquainted with the literary texts helps the players to "create logically distinct, though imaginatively related, [storyworld] through modifications and transpositions that alter existing content" (Ryan 2014: 42). By design, Gormenghast: A Board Game is set in the world of the novels: "Welcome to Gormenghast, that massive and crumbling stone edifice which provides the backdrop to this game" (Cooke 2013b: 2). It uses a selection of characters taken directly from the pre-texts, and relates to their other components, such as social rules and values or events. The main difference is that

In this board game each player takes on the role of a "kitchen rat" similar to Steerpike in the book. Like Steerpike you have the same murderous desire for power. Your goal is to accumulate as much influence as you can (in the form of Victory Tokens), rise to the top and become Master of Ritual. (Cooke 2013b: 2, emphasis mine)

4 The outer dimension is a term borrowed from Andrzej Dróżdż (2009: 19-24), originally applied to codex books (see also Mochocka 2015: 40). 
Playability requires that the players (2 to 4 people) participate in the game on equal grounds, hence the new, nameless, player characters, and no direct depiction of either Titus Groan, or Steerpike (the protagonist and the antagonist of the novels). The variability of the game - to be a game, a playable system has to provide a variable and quantifiable outcome (Juul 2003: n.p.) — means that each of these characters has got an equal chance to win the game, thus creating a different emergent narrative:

To acquire Victory Tokens players move characters around the board to complete various intrigues (detailed on Plot Cards). When a player completes a plot they gain Victory Tokens. The first player to acquire 9 (or more) Victory Tokens wins the game" (Cooke 2013b: 2).

The game recreates the pathos of the novels in that the players can compete with each other to bend characters such as Nanny Slagg or Lady Fuchsia to their will, make them move from one place to another and collect some items on the way. The thirty Plot Cards are written in the vein of Peake's novels, and suggest narrative situations in which player characters are active agents, such as, for example, "Lady Fuchsia's romantic nature is not easily exploited, but in the serene surroundings of the North Cloister, read her the more affectionate passages from one of the Books of Martrovian Drama to excite her passions" (the text on one of the Plot Cards, original emphasis). This is a Pick-up and Deliver mechanics - one has to pick up an item and gets rewarded for delivering it to a prescribed location.

Another application of game mechanics to transmediate the pathos is the use of Tile Placement (combined with Hand Management) to set up and expand the board. At the beginning of the game session, each player can add a tile (representing a fragment of the castle) to the tile depicting the Tower of Flints, placed at the middle of the table (Cooke 2013b: 4). At this stage, the exits depicted on the tiles have to match the entrances. During the play, however, if a character controlled by a player cannot move forward ("If you exit a Castle Tile through an exit which has no adjoining tile"), a new tile is drawn and added to the board (Cooke 2013b: 7). What is crucial, "unlike Set Up the only exit that needs to match is the one the character has just passed through" (Cooke 2013b: 7). Such an arrangement results in the creation of a chaotic, illogical, and incomprehensible space, very much akin to the one presented by Peake. What serves as the safeguard of replayability (from the player's perspective it should be possible to play the game more than once, and each game session should be equally rewarding) is also very well attuned with the main characteristics of the pre-textual storyworld.

The close-knit relationship depicted by Peake between the characters and their spaces has been lost due to the replayability requirement. In the game, the characters cannot be ascribed to a specific space. The players (controlling the characters) need agency, so the characters have to be able to move across the board freely. The Artifact Tokens are distributed (heads down) over the board at random during the Set Up phase, the ones representing characters replaced later with Character Pieces (Cooke 2013b: 4). What is preserved, however, is the possible experience of the struggle against the incomprehensible space inside the castle, as the characters perform tasks specified on the Plot Cards. This is, of course, a possibility, opened by the structural characteristics of the game-as the case is with game systems in general, the actual realisation of gameplay and the following game experience depends on the choices, attitudes, and expectations of the specific player, and 
could be much different. For example, players might engage in a purely gamist (that is, focused on strategic and tactical immersion) play, eschewing most narrative elements (it is a known fact that over time players tend to pay less and less attention to the flavours on the cards, for example).

The thirty-pages long Book of Ritual could be considered as either intradiegetic or extradiegetic element (Ryan 2014: 37), as it contains mechanical directions - e.g. "All players draw 1 Action Card" (Cooke 2013c: 17) — and at the same time existing as an artefact within the storyworld (Ryan 2014: 37). In the novel, the characters follow the absurd and oppressive ancient lore exemplified in the Book of Ritual. This social rules and values component of the storyworld has been been transferred to the board game by means of Hand Management and Dice Rolling mechanics:

In the Action Deck there are 12 Ritual Cards, each with the ritual symbol on them. These cards cannot be discarded, and will slowly fill up your hand if not played. When a Ritual Card is played, roll the Ritual die and consult the Book of Ritual to find out which ritual is invoked and follow the instructions. (Cooke 2013b: 7)

Consulting the Book of Ritual is therefore inevitable, but can be tactically postponed. The ritual is chosen by chance (roll die) and may result in consequences both beneficial or detrimental to the strategy of the players. Often, the ritual concerns moving a character to a given space, e.g. "Move 1 servant character of your choice to the Great Kitchen. If this tile is not in play, find it in the castle tile deck and place it into play" (Cooke 2013c: 14, original emphasis). As the game is competitive, this allows the player who rolls the die to undermine the strategies of the other players, but some of the rituals entail consequences that concern everyone or everyone in a given situation, e.g. "All players discard 1 card (...)" (Cooke 2013c: 22) or "Remove all influence tokens from all noble characters" (Cooke 2013c: 24, original emphasis). In the Gormenghast series the rituals are spatially determined as well, but this time the game goes much further in stressing their illogical and repressive mechanisms.

\section{Final remarks}

Any adaptation of a literary narrative to a board game must include two major operations:

1. Visualisation, i.e. transmediation of the narrative space from an imagined construct created by verbal descriptions (only sometimes accompanied by artwork) to a physical and visual space of the game board and other elements (cards, tokens) (Wolf 2012). The affordances of a board game include visual art, fragmentation of elements, their spatial arrangement (e.g. tokens and pawns on the board) and moveability, with some limited potential for verbal descriptions as well. In short: imagined space becomes physical space, the outer dimension of the board game;

2. Interactivation of narrative events (both world events and character actions) into a system of rules and available actions defined by game mechanics and game elements (Wolf 2012). Together, the collection of game elements (board, cards, tokens, dice, pawns, units which represent elements of the storyworld from the source texts) and game mechanics allow for meaningful actions that simulate the behaviours, processes, conflicts, and events from the source narrative. 
In games with a strong element of role-playing and characterisation, the transmediation of characters could be analysed as the third major operation. In Gormenghast it does not seem necessary: here, the player characters are characterised only by their goals, actions, and tokens of influence (therefore included in interactivation). Characters represented as pawns are objects of little significance, transmediated in the processes of visualisation and interactivation as little more than "resources" constrained by the space of the board and moved around it by forces they cannot control (not unlike in the original narrative).

Philip Cooke's design choices seem to support the ludonarrative coherence of the game, at the same time reflecting some of the spatial characteristics of the literary texts that it transmediates. The mechanics used match the themes introduced by Peake: chaos, indeterminacy, isolation, and enclosure, and the related reader's experience. By using tiles and tokens representing the objects and people that can be found there, the spatial structure of the game emulates the space presented in the Gormenghast. The dynamics of the game is similar to the spatially conditioned narrative situation present in the novels.

\section{Bibliography}

Alber Jan (2009), Impossible Storyworlds — and What to Do with Them, "StoryWorlds: A Journal of Narrative Studies", Vol. 1.

Alber Jan, Iversen Stefan, Skov Nielsen Henrik, Richardson Brian (2010), Unnatural Narratives, Unnatural Narratology: Beyond Mimetic Models, "Narrative", Vol. 18.

Binns Ronald (1979), Situating Gormenghast, "Critical Quarterly" 21.1.

Berlin Brent, Key Paul (1991), Basic Color Terms: Their Universality and Evolution, University of California Press, Berkeley, Los Angeles.

Booth Paul (2015), Game Play: Paratextuality in Contemporary Board Games, Bloomsbury Publishing, Kindle Edition.

Cooke Philip (2013a), Gormenghast: A Board Game set in the World of Mervyn Peake, Sophisticated Games, Cambridge and The Overlook Press, New York.

- (2013b), Rules [in:] Gormenghast: A Board Game set in the World of Mervyn Peake, Sophisticated Games, Cambridge and The Overlook Press, New York.

- (2013c), Book of Ritual [in:] Gormenghast: A Board Game set in the World of Merynn Peake, Sophisticated Games, Cambridge and The Overlook Press, New York.

Dróżdż Andrzej (2009), Od liber mundi do hipertekstu. Ksią̇ka w świecie utopï, Biblioteka Analiz, Warszawa.

Fiedler Leslie (1990), The Substitution of Terror for Love [in:] The Gothic Novel: A Casebook, ed. V. Sage, Macmillan, London. 
Gardiner-Scott Tanya (1988), Mervyn Peake: The Relativity of Perception, "Journal of the Fantastic in the Arts", Vol. 1.

Gomel Elena (2014), Narrative Space and Time. Representing Impossible Topologies in Literature, Routledge, New York-London.

Głowiński Michał, Okopień-Sławińska Aleksandra, Sławiński Janusz (1991), Zarys teorii literatury, WSiP, Warszawa.

Hocking Clint (2009), Ludonarrative dissonance in Bioshock: The problem of what the game is about [in:] Well Played 1.0, ed. D. Davidson, ETC Press.

Hutcheon Linda (2006), A Theory of Adaptation, Routledge, New York-London.

Inagrden Roman (1988), O diziele literackim, trans. M. Turowicz, PWN, Warszawa.

Jackson Rosmery (1981), Fantasty: The Literature of Subversion, Methuen, London-New York. Jenkins Henry (2004), Game Design as Narrative Architecture [in:] First Person: New Media as Story, Performance, Game, eds N. Wardrip-Fruin, P. Harrigan, MIT Press, Cambridge.

Johnson Mark (1987), The Body and the Mind: The Bodily Basis of Meaning, Imagination, and Reason, University of Chicago Press, Chicago-London.

Juul Jesper (2003), The Game, the Player, the World: Looking for a Heart of Gameness [in:] Level Up: Digital Games Research Conference Proceedings, eds M. Copier, J. Raessens, Utrecht University, Utrecht, http://www.jesperjuul.net/text/gameplayerworld [access: 15 February 2017].

Lakoff George, Johnson Mark (1980), Metaphors We Live By, Chicago UP, Chicago.

Lotman Jurij (1984), Struktura tekstu artystycznego, trans. A. Tanalska, PIW, Warszawa.

Mochocka Aleksandra (2015), Polskie gry plansqowe oparte na utworach literackich — rekonesans, "Biblioteka postscriptum polonistycznego", nr 5.

Morgan Edwin (1960), The Walls of Gormenghast: An Introduction to the Novels of Mervyn Peake, "Chicago Review", Vol. 14. No. 3.

Peake Mervyn (1992), The Gormenghast Trilogy: Titus Groan, Gormenghast, Titus Alone, Mandarin, London.

Raban Johnatan (1968), The Technique of Modern Fiction, University of Notre Dame Press, London.

Ryan Marie-Laure (2001), Narrative as Virtual Reality. Immersion and Interactivity in Literature and Electronic Media, The Johns Hopkins UP, Baltimore.

- (2014), Story/Worlds/Media. Tuning the Instruments of a Media - Conscious Narratology [in:] Storyworlds across Media. Toward a Media — Conscious Narratology, eds M.-L. Ryan, J.N. Thon, University of Nebraska Press, Lincoln-London.

Salen Katie, Zimmerman Eric (2004), Rules of Play. Game Design Fundamentals, MIT Press, Cambridge.

Sanders Joe (2001), Recognizing the Peake Achievement, „Science Fiction Studies”Vol. 28. No. 3 (Nov.).

Schlobin Roger C., Schlobin Roger E. (2000). "rituals' footprints ankle-deep in stone": The Irrelevancy of Setting in the Fantastic, ,Journal of the Fantastic in the Arts”, Vol. 11, No. 2 (42).

Spencer Sharon (1971), Space, Time and Structure in the Modern Novel, The Swallow Press Inc., Chicago.

Sussner Julia, Lohse Ludvig, Thomas Maureen, Garcia Gustavo, Alonso Isabel, Munoz Alberto (2006), 3D Navigable Interface for Interactive Movie Gormenghast Explore [in:] Proceedings of the Second International Conference on Automated Production of Cross Media Content for Multi-Channel Distribution (AXMEDIS 06), IEEE Computer Society, Washington. 
Tompkins Joyce M.S. (1971), The Gothic Romance [in:] The Gothic Novel: A Casebook, ed. V. Sage, Macmillan, London.

Winnington G. Peter (2006), The Voice of the Heart. The Working of Mervyn Peake's Imagination, Liverpool UP, Liverpool.

Wolf Mark (2012), Building Imaginary Worlds: The Theory and History of Subcreation, Routledge,

New York-London, https://books.google.pl/books?id=rc6HgH34s0wC\&printsec $=$ fron tcover\&dq $=$ Wolf + Building\&hl $=$ pl\&sa $=$ X\&redir_esc $=\mathrm{y} \# \mathrm{v}=$ onepage\&q\&f $=$ false $[$ access: 15 February 2017]

Zgorzelski Andrzej (1975), Kreacje świata sensów, LTN, Lublin. 